Ciencia y Educación, Vol. 5, No. 2, mayo-agosto, 2021

ISSN (impreso): 2613-8794・ISSN (en línea): 2613-8808

DOI: https://doi.org/10.22206/cyed.2021.v5i2.pp7-24

\title{
Sujetos y afectos en la inserción al mundo profesional de la docencia
}

\author{
Subjects and affections in the insertion to the professional \\ teaching field
}

Valeria Bedacarratx ${ }^{a}$ ORCID: 0000-0002-1748-668X

Recibido: 24/09/2020 - Aprobado: 30/11/2020

Cómo citar: Bedacarratx, V. (2021). Sujetos y afectos en la inserción al mundo profesional de la docencia. Cienciay Educación, 5(2), 7-24. https://doi.org/10.22206/cyed.2021.v5i2.pp7-24

\section{Resumen}

El artículo tiene como objetivo exponer algunos de los modos en que los estudiantes futuros docentes, en situación de práctica pre-profesional, viven y se apropian de la cultura profesional de la que pretenden formar parte, construyendo sus propias versiones respecto a la naturaleza del trabajo docente. La investigación se fundamenta en un enfoque psicosocial que aborda los aspectos subjetivos de la formación y socialización profesional docente. Desde una metodología cualitativa y con una muestra intencional constituida por tres grupos de estudiantes, el dispositivo utilizado para la obtención del material fue el de grupo de reflexión con modalidad operativa. El análisis muestra cómo el contacto con el objeto real de trabajo suscita emociones ambivalentes: los niños, la sociedad contemporánea, el contexto laboral y la propia formación se viven como obstáculos en la consecución de la tarea, en "contra" de los cuales es necesario trabajar, en búsqueda de su transformación.

Palabras clave: docencia, formación docente, socialización, práctica pedagógica, Psicología Social.

\begin{abstract}
The objective of this article is to give an account of some ways in which future teacher students, in a pre-professional practice situation, live and appropriate the professional culture in which they try to be included, building their own versions regarding the nature of the teaching work. The research is based on a psychosocial approach that addresses the subjective aspects of professional teacher training and socialization. From a qualitative methodology, and with an intentional sample made up of three groups of students, the device used to obtain the material was the reflection group with operational modality. The analysis shows how the contact with the real object of work arouses ambivalent emotions: children, contemporary society, the work context and teacher training itself are experienced as obstacles in the achievement of the pedagogical task, against which it is necessary to work, in order to achieve its transformation.
\end{abstract}

Keywords: Teaching profession, teacher education, teaching practice, socialization, Social Psychology.

\footnotetext{
a Consejo Nacional de Investigaciones Científicas y Técnicas. Centro de Investigación y Transferencia Santa Cruz (CONICET-CIT SC), Argentina. Correo-e: vbedacarratx@conicet.gov.ar
} 


\section{Introducción}

El campo problemático de la investigación en la que los resultados aquí expuestos se enmarcan se estructuró en torno al interés por conocer las formas prototípicas en que se asume la posición docente en la iniciación profesional y las formas en que ellas dan cuenta de los rasgos propios de la cultura y dramática profesional (reconfigurados) en un contexto de declive institucional (Dubet, 2002). El planteo sociológico del citado autor postula que asistimos al declive del programa institucional de la modernidad, anunciado e inscripto en la génesis de su conformación y producido por la exacerbación de sus contradicciones latentes. La hipótesis que desarrolla Dubet es que se trata de una crisis

del propio proceso de socialización, una crisis, inscrita en una mutación profunda del trabajo sobre el otro (...) ligada a las transformaciones de la modernidad que trastocan el ordenamiento simbólico de la socialización, de la formación de los individuos y, por consiguiente, de la manera de instituir a los actores sociales y a los sujetos. (Dubet, 2007, p. 41)

En ese marco, y entendiendo que el hacer docente es una práctica de intervención social que participa del mandato de socialización y transmisión del legado cultural de una sociedad a las nuevas generaciones, se erigió como central la pregunta relativa a los modos en que los jóvenes futuros nuevos docentes tramitan el sufrimiento y las ansiedades que provoca el ejercicio de la tarea en el mencionado contexto, articulada al análisis de su impacto en las prácticas pedagógicas y en la configuración subjetiva de las nuevas generaciones de maestros.

Derivada de dicha investigación, esta presentación se sitúa en el campo de la psicología social en su vertiente grupal e institucional y, desde allí, expone la interpretación de un material discursivo producido por estudiantes futuros maestros mexicanos, procurando aportar a las reflexiones y discusiones propias del campo de la formación docente inicial. Se trata de una confluencia de campos factible desde un posicionamiento epistemológico que parte de reconocer el carácter complejo de las prácticas sociales: complejidad imposible de ser asida desde las falsas escisiones (de relación unidireccional) con las que tradicionalmente se han abordado los problemas de la formación y la práctica profesional (relación teoría-práctica, intelecto-emoción, pensamiento-acción) (Schön, 1998; Alliaud, 2017; Sanjurjo, 2017; Tardif y Moscoso, 2018). Siempre desplegada en escenarios singulares, "bordeados y surcados por el contexto" (Edelstein y Coria, 1995), esta práctica social puede describirse desde un conjunto de rasgos que la definen como altamente compleja, tanto por la multiplicidad de dimensiones que operan en ella de forma simultánea, como por el hecho de que tiene como protagonista a un sujeto (psíquico y social) con marcos interpretativos que sostienen sus formas de pensar y hacer (Edelstein y Coria, 1995; Alliaud, 2017; Sanjurjo, 2017; Tardif y Moscoso, 2018).

Desde este posicionamiento, se asume, entonces, que los procesos de construcción y transformación psicológica y social -que se despliegan en las prácticas pedagógicas y en los procesos de socialización profesional- solo pueden ser entendidos en interconexión e interdependencia mutua (Kaplan, 2018). En ese marco, la noción de subjetividad se erige como conceptualización central del contexto teórico de esta investigación, entendiéndola como el conjunto de procesos intra e intersubjetivos, conscientes e inconscientes, individuales y colectivos por el que el sujeto (futuro docente) se constituye (internamente) como tal (Bedacarratx, 2012), apropiándose de e incorporándose a una cultura (profesional) en el entramado de dos órdenes irreductibles e inseparables: el del psiquesoma y el histórico-social (Ramírez Grajeda y Anzaldúa Arce, 2017).

De este modo, el análisis propuesto conlleva el esfuerzo de reconstrucción de las articulaciones entre la realidad psíquica de los sujetos singulares y el conjunto intersubjetivo del que forman parte $-y$ al que dan consistencia- (Remedi, 2004). A los efectos de esta presentación, la tarea analítica expuesta estará centrada en la identificación de: por un lado, las formas de caracterizar y vivenciar el trabajo docente en las primeras experiencias profesionales; por otro, el modo en que 
esa caracterización se vincula a los rasgos socioculturales e institucionales que atraviesa y hace de marco en el desarrollo de la tarea docente.

Luego de realizada la contextualización metodológica en la que se produjo el material empírico (apartado Metodología), el análisis desarrollado en el apartado Resultados da cuenta de una constante referencia, tanto al atravesamiento social y subjetivo que supone el desarrollo de la tarea como a las novedades que esta conlleva en un contexto cultural de transformaciones, contrastantes con las características de la escuela, la infancia y la sociedad de épocas pasadas, que jóvenes futuros docentes habrían vivenciado cuando niños.

Sobre el final, se propone una reflexión en torno al potencial de la formación inicial respecto del trabajo con la dimensión subjetiva de los sujetos en formación, previo postular una lectura global del material analizado, del que emerge la persistente y constante referencia a ciertos aspectos del hacer docente que se interpretan como "novedosos" y propios de un escenario social que contrasta con el de épocas pasadas: situación que suscita emociones ambivalentes y posicionamientos diversos y que -desde el discurso de los entrevistados- reubicaría el lugar simbólico que históricamente han ocupado en el campo social escuelas, maestros, padres y alumnos. En ese marco, los contextos áulicos, institucionales y laborales se viven, predominantemente, como obstáculos, tanto para el logro de los objetivos perseguidos como para acercarse al "deber ser" pautado y construido durante la formación inicial.

\section{Metodología}

El análisis aquí presentado corresponde a una instancia de relectura y reinterpretación del material discursivo producido en un trabajo de campo realizado con practicantes de la Licenciatura en Educación Primaria de la mayor y más antigua institución formadora de docentes de la ciudad de México. La estadía en el campo (tanto en la institución formadora como en las escuelas de nivel primario receptoras de sus practicantes) tuvo una duración de ocho meses y se trabajó con una muestra intencional en la que los sujetos fueron seleccionados siguiendo el criterio de pertenencia a un grupo-clase que estuviera cursando alguna de las instancias de prácticas pre-profesionales en el marco de la licenciatura citada.

Pretendiendo contribuir a una caracterización del atravesamiento subjetivo de la socialización profesional en el marco del contexto sociocultural contemporáneo, la recolección de los datos que aquí se analizan estuvo orientada por el objetivo de comprender: ¿cómo los jóvenes futuros docentes viven y se apropian de la cultura profesional de la que pretenden formar parte? ¿Cuáles movimientos subjetivos realizan para poder asumir la tarea docente? ¿Cuáles valores, creencias y emociones emergen al asumir la tarea docente? ¿Cuáles versiones construyen -en sus primeras experiencias de intervención pedagógica- respecto de la naturaleza del trabajo docente?

Metodológicamente, estas preguntas se abordaron desde una línea de indagación que privilegió estrategias propias de la investigación cualitativa, con enfoque interpretativo: la recolección y el análisis del material estuvieron centrados en la búsqueda de sentidos y en la comprensión de la subjetividad y los significados de los que son portadores/constructores los sujetos involucrados.

Teniendo como marco una estrategia metodológica más amplia (que incluyó la obtención de datos a través de otras herramientas), los resultados expuestos en el presente artículo corresponden al análisis de las producciones discursivas de la muestra antes mencionada, constituida por tres grupos (preexistentes) de practicantes (mayormente compuestos por mujeres, con un rango etario de entre 19 y 25 años): un grupo de dieciocho estudiantes de tercer semestre, un grupo de siete estudiantes de séptimo semestre y un grupo de ocho estudiantes de octavo semestre. Ese material fue producido con el dispositivo de grupo de reflexión con modalidad operativa en dos sesiones de hora y media cada una (con cada uno de los grupos). Al respecto, resulta pertinente apuntar que

... utilizar dispositivos grupales para la investigación, significa, entre otras cosas, que los materiales de grupo van a ser producidos en condiciones 
controladas por un encuadre y que en esa producción de material interviene el investigador. Esta modalidad de trabajo en donde el investigador entra a formar parte activa del campo de observación es lo que le da al método (...) su carácter operativo. La intervención del investigador consiste en la coordinación de un proceso (...): el elemento crítico de intervención consiste en el establecimiento de la tarea a proponer al grupo, misma que deriva del diseño de investigación y que es el elemento clave del encuadre, ya que el proceso grupal se constituye a partir de la producción de un grupo que trabaja alrededor de una tarea. (Baz, 1996, pp. 62-63)

El trabajo con grupos de reflexión constituyó una vía óptima de acceso a emergentes, cadenas de significantes y figuras metafóricas (Baz, 1998; Aubusson, Harrison y Ritchie, 2006, como se citó en Hernández Mella, Pacheco-Salazar, Liranzo Soto y Jiménez Soto, 2018) que dieron cuenta de significados, emociones, valores y sentidos a los que aparece asociado el trabajo docente.

Atendiendo a lo hasta aquí expuesto, la indagación se abordó como un estudio de casos, como

una forma de investigación empírica que aborda fenómenos contemporáneos, en términos holísticos y significativos, en sus contextos específicos de acontecimiento, orientada a responder preguntas de 'cómo' y 'por qué' suceden las cuestiones bajo examen (...) [procurando] captar la complejidad del contexto y su relación con los eventos estudiados. (Neiman y Quaranta, 2006, p. 230)

Desde aproximaciones sucesivas, y desde una flexibilidad teórica que permitiera un juego de modificaciones entre el dato empírico y los aportes conceptuales diversos (Achilli, 2000), se procedió a la construcción de categorías analíticas de diferentes niveles, usando, de modo progresivo, las conceptualizaciones provenientes de los campos disciplinares usados como referentes. Además, en lo relativo al análisis del material, la concepción operativa de grupo conlleva un modo de abordar e interpretarlo, a partir del proceso grupal, entendiendo al grupo como una estructura: relación de relaciones específicas, que hacen que el grupo sea precisamente lo que es. Así, (...) el grupo como tal produce un discurso (...) la comunicación que se genera en el grupo no debe "escucharse" como producto individual, sino como resultado de un proceso grupal, que a su vez produce efectos en el proceso mismo del grupo, que se moviliza y reconstruye como colectivo. El discurso se hace en grupo, y a su vez, hace al grupo. (Araujo y Fernández, 1996 , p. 248)

\section{Resultados}

Hecha la contextualización teórico-metodológica de la investigación, se presenta, en lo que sigue, la interpretación del material empírico, organizada en torno a tres ejes de significados que condensan y permiten comprender los modos en que los sujetos futuros docentes asumen sus primeras experiencias de intervención pedagógica y se posicionan en el campo socio-profesional de la docencia. Las palabras y frases cortas entrecomilladas corresponden a palabras textuales registradas en el marco de las sesiones de reflexión llevadas a cabo con los grupos cuya producción se expone en cada uno de los siguientes tres apartados.

\section{El trabajo docente interpelado por las infancias}

La reflexión del grupo de estudiantes del tercer semestre de la Licenciatura en Educación Primaria estuvo atravesada por la ambivalencia con la que se vive el trabajo con "los niños de hoy", quienes, desde la perspectiva de los practicantes, atribuyen sentido a la tarea docente y a quienes se los caracteriza, fundamentalmente, como alumnos "diferentes a los de antes" (como eran ellos). Los niños de hoy son significados como un componente/emergente de un contexto sociohistórico cuyos discursos y cuyas prácticas desvalorizan la función social de la escuela y el trabajo docente, situación que se asocia al debilitamiento de la autoridad del maestro para "pararse al frente", "ser atendido" y "llevar adelante una clase". 
Esta caracterización del contexto sociocultural en el que se desarrollan las prácticas se contrapone a un referido pasado imaginario (social y pedagógico) signado por la inhibición de la libertad por parte de las generaciones adultas sobre las más jóvenes, situación criticada a la vez que, implícitamente, añorada: en tanto eran aquellas circunstancias las que prefiguraban un lugar previsible tanto para un niño-alumno "pasivizado" y "fácil de controlar" como para un docente dotado de la autoridad para ejercer ese control. Es por eso que, en la referencia ańorada/criticada a ese pasado imaginario, el grupo alude con recurrencia a la necesidad y el deseo no solo de cambiar las formas tradicionales de enseñar y de vincularse con los niños, sino también de modificar la percepción que la sociedad tiene en torno al trabajo docente y, específicamente, con relación al trabajo con los niños de hoy.

Este "deseo de cambiar", de "romper con las formas tradicionales" hoy perimidas, junto con "el amor a la profesión" y "el deseo de ayudar a otros a salir adelante", se constituyen, desde el discurso grupal, como los principales pilares que sostienen la decisión de ser maestros, más allá de la desvalorización generalizada respecto al trabajo docente o de lo que los otros significativos (padres, hermanos, amigos) piensen respecto a esa elección. Desde el planteo de los entrevistados, el ejercicio de la tarea y la superación de las dificultades que pudiera implicar es posible por el amor a ella y a los niños (portadores del futuro que ellos, como docentes, colaborarán a forjar). La vocación de servicio y un compromiso social de cambio aparecen complementando ese amor-vocación-convicción, todo lo cual, desde la perspectiva grupal, es factible de acrecentarse a medida que se van acumulando experiencias en la trayectoria profesional.

Identificándose como una nueva generación de maestros, el lugar que se autoasignan los miembros del grupo en la escena educativa es el de constituirse en una alternativa a la escuela y a la "enseñanza tradicional": alternativa sostenida en los principios del constructivismo y que propugnaría una relación pedagógica basada en un vínculo más libre, signada por el "dar y recibir" mutuos (entre docente y alumnos). Al respecto, lo primero que el grupo señala es la posibilidad de recibir reconocimiento: el deseo de ser reconocido por los alumnos, de "perdurar en el recuerdo" cuando los niños sean adultos. La gratificación del trabajo pasaría así por el cariño de los niños mientras son alumnos y por un reconocimiento a futuro cuando ya no lo sean.

Este carińo y reconocimiento aparece condicionado o determinado por aquello que ellos hayan podido dar como maestros: lo que el maestro reciba de los alumnos es directamente proporcional al amor y a los conocimientos significativos que les haya proporcionado. Los estudiantes comparten: "tenemos que darles mucho más que conocimientos, incluso cubriendo aquello que la propia familia no les dé", "darles algo que tenga sentido para ellos y que les sirva para su vida", "tenemos que tener aquello que queremos darles". Con relación a esto es recurrente la idea de la formación, de la capacitación, de la preparación (especializada, específica, profesional) como la oportunidad de adquirir aquello que luego habrá que dar y transmitirse a los niños. Desde la perspectiva de los futuros docentes, excediendo ampliamente la "mera transmisión de conocimientos", el núcleo central del hacer del maestro se metaforiza como "acto de entrega": "darlo todo, hasta la vida", con la doble significación que puede tener esta frase (parirlos/morir por ellos).

Asimismo, lo que los niños tienen para dar se significa explícitamente como fuente de satisfacción, pero también, más implícitamente, como fuente de persecución (en tanto también dan un juicio -que puede ser negativo- acerca de su desempeño), de allí que las significaciones relativas a esta relación (docente-alumno) giran en torno a dos sentimientos: el temor (a no ser reconocidos, a ser rechazados, a no ser "atendidos" en la clase) y el amor (como motor de la relación y sustento clave de la elección profesional).

Ahora bien, el grupo plantea que, en esta dinámica del dar y el recibir, se generan un conjunto de expectativas mutuas: por parte de los futuros maestros, el ser reconocidos; por parte de los alumnos, el ser destinatarios de propuestas que los reconozcan como sujetos activos en la construcción de conocimientos. Si bien en este punto el grupo se posiciona 
desde el lugar específico de practicante, a lo largo del proceso grupal prima un posicionamiento más amplio, ligado al lugar del enseñante: las experiencias que se mencionan no son solo las que han vivido en las prácticas, sino también las que portan como exalumnos de primaria, lo cual habla de la relevancia que tienen las biografías escolares en la comprensión de los fenómenos sobre los que se está reflexionando. En este sentido, la producción grupal se mueve en un horizonte temporal comenzando por un presente que genera inseguridades, temores y angustias, un pasado criticado/añorado y un futuro prometedor sobre el que se depositan expectativas de cambio, del cual la nueva generación de maestros sería protagonista.

Por otra parte, en la caracterización que el grupo hace de los niños que han tenido como alumnos, se alude también a sus orígenes y contextos sociofamiliares. En esa alusión, el maestro aparece como aquel que puede suplir las carencias del hogar ("dando lo que este no da”) y el que tiene que comprender la situación singular de cada sujeto. Esta situación se plantea como un factor que diversifica su trabajo: en contraste con los planteos de la pedagogía tradicional, se advierte que no sería pertinente "dar a todos lo mismo"; por el contrario, se asume que el maestro debe atender a la heterogeneidad y diversidad propia de cada salón de clases, y, si es necesario, "partirse en varias partes" no solo para dar a cada alumno lo que necesite, sino también para responder a las múltiples demandas y exigencias del contexto social e institucional. Así, se identifica un incremento en la complejidad del oficio por el que han optado y que, contrariamente a lo por ellos vivenciado, el sentido común caracteriza como sencillo, fácil y plausible de ser ejercido por "cualquier adulto con conocimientos básicos".

El trabajo con los niños quedó también referenciado en la dificultad por trabajar lo grupal, cómo trabajar en equipos con los niños con metodologías que le den protagonismo, voz y participación. En este punto, los futuros maestros manifiestan estar desprovistos de experiencias sobre las cuales construir un saber hacer profesional que les permita implementar tales metodologías; al mismo tiempo, los niños son concebidos como sujetos escolarizados que "no saben", que "no están acostumbrados" a trabajar con metodologías diferentes a las tradicionales, razón por la cual ellos y sus propuestas quedan expuestos al fracaso.

Aunque los practicantes se consideran portadores de una visión alternativa del aprendizaje (como proceso creativo y activo) y del conocimiento (como producto de una construcción del sujeto), a partir de los cuales propiciar un cambio en las formas tradicionales de enseńanza, parecen sentirse carentes de una congruente concepción de disciplina que habilite y dé lugar a la actividad y protagonismo al sujeto que aprende. La noción de disciplina asociada al silencio, a la imposición de un orden témporo-espacial, a la inactividad corporal del niño, a la idea de "manejo de grupo" (idea esta última que estaría muy presente en las devoluciones de los profesores de práctica) "choca" con la idea del niño contemporáneo, como un sujeto que, esencialmente, hace ruido, es activo, se mueve, cuestiona, pero, a partir de eso, puede aprender.

Es de mencionar que aquello que en un inicio apareció vinculado con las dificultades por el trabajo grupal con los niños paulatinamente fue desplazándose hacia el contexto laboral, aludido a través de diversas circunstancias y distintos sujetos: la dificultad de trabajar en equipo con el maestro titular, con los padres de familia, con la institución escolar y la institución formadora. Se incorporaron, así, otros componentes en la descripción de las dificultades propias de la tarea docente que, solo en algunos momentos, descentraron el discurso de la relación con los niños.

Así, no solo los rasgos particulares de las infancias actuales y su heterogeneidad presente en los salones de clase son vivenciados como obstáculos inherentes al trabajo docente, sino también los paradójicos discursos del contexto laboral y social. Paradójicos, en tanto se asigna un alto encargo social a la tarea de educar, pero con una importante depreciación profesional y salarial para quienes están llamados a esa tarea: el maestro debe responder a diversas y diversificadas demandas y su saber hacer no puede construirse solo en base a perspectivas teóricas y convicciones personales.

Por el contrario, se trata de un saber hacer que -como lo advierten los miembros del grupo- está 
inevitablemente nutrido de los modos o modelos de enseñanza que han vivenciado como alumnos y que, simultáneamente, son los que se pretenden cambiar. Los sentimientos de inseguridad e incertidumbre generados por la implementación de metodologías en las que ni ellos ni los alumnos "se sienten cómodos" parecieran conducir a un repliegue en las viejas formas conocidas que dan seguridad y mejores resultados en la relación docente-alumno (ver Esquema 1). Así, la adaptación del nuevo maestro al medio social en el que se inscribe su trabajo, de los contenidos que enseńa y de sus metodologías -reproduciendo y repitiendo las formas pedagógicas que se critican- constituye una "salida" razonable y no deseada para sobrevivir -no solo como practicante, sino también como maestroen el contexto laboral escolar.

\section{Esquema 1}

El trabajo con las infancias de hoy

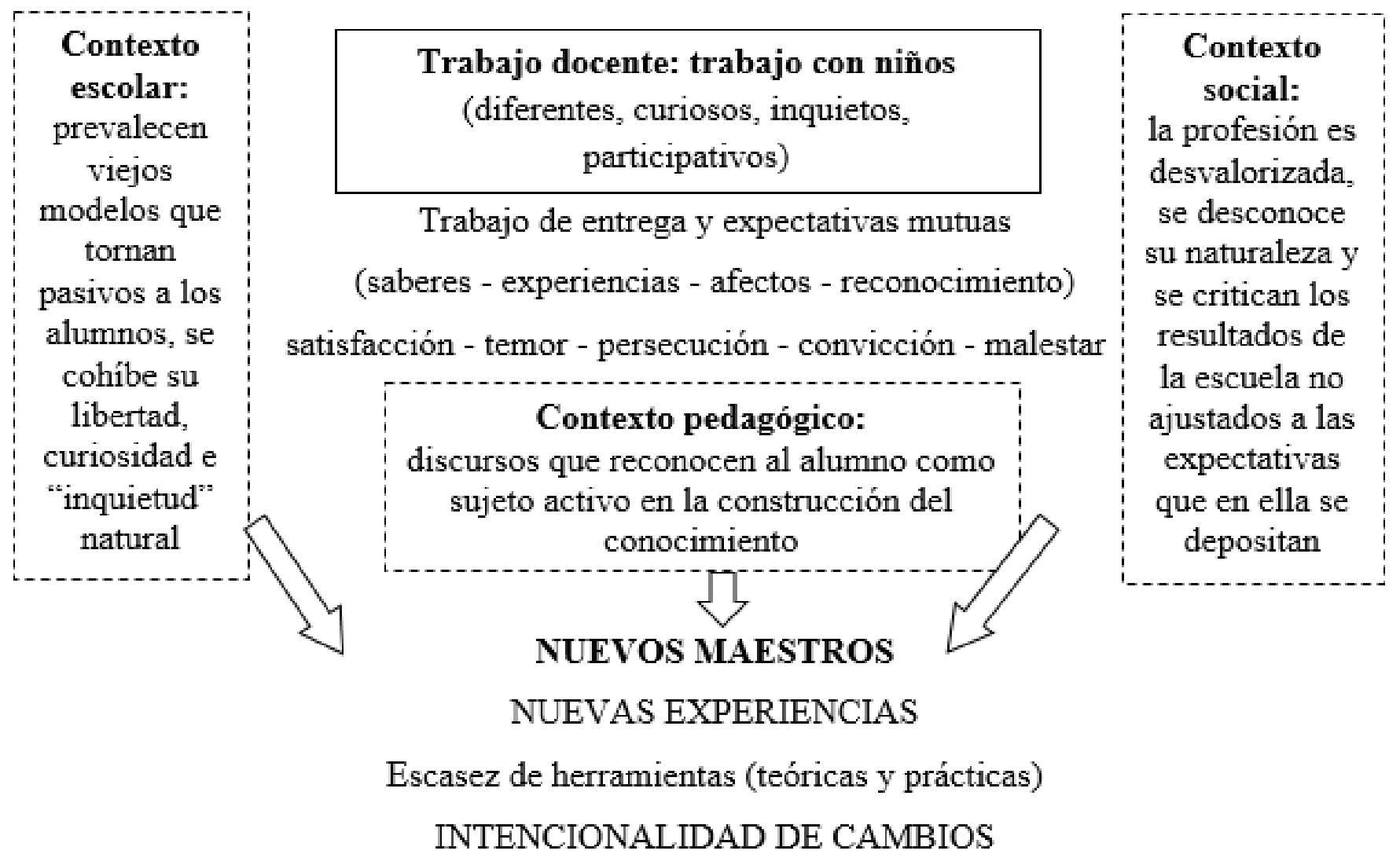

Cambiar la escuela, la sociedad, los sujetos<smiles>C1CC2CCC2C1</smiles>

Dificultades para ocupar el lugar de maestro dotando de protagonismo a los alumnos<smiles>C1CC2CCC2C1</smiles>

REPLIEGUE sobre las formas conocidas y criticadas 


\section{Un trabajo para revolucionar, cambiar, adaptarse...}

En el grupo del séptimo semestre la reflexión comenzó girando en torno a la idea de la responsabilidad de la labor, significada desde dos lugares opuestos que fueron objeto de discusión y enfrentamiento de posicionamientos: la responsabilidad por "cambiar"-"revolucionar" (las formas tradicionales de enseñanza, la visión que la sociedad tiene de la escuela, la concepción que se tiene del aprendizaje; todo esto para evitar la reproducción de esquemas impuestos) confrontada con la responsabilidad por conservar el orden social, por mantener los valores de la sociedad y la escuela.

El conflicto entre percepciones queda omitido cuando el grupo plantea que, además de la responsabilidad, es el amor lo que signa el trabajo docente: el amor hacia los niños es lo que explicaría la opción por la carrera docente. Una carrera que, al tiempo que sería "muy pesada” y requeriría de "muchos esfuerzos, supondría asumir la responsabilidad de sentar las bases para "ir mejorando la sociedad" y sortear los inconvenientes para responder a los niños, "dejarlos sin dudas".

Desde la perspectiva del grupo, allí radica la relevancia social del trabajo del maestro, quien queda ubicado como el que "prepara a los niños para vivir en sociedad", debiendo ser el ejemplo que los alumnos habrán (querrán) de imitar. Asimismo, y en tanto el aula queda entendida como espacio microsocial que refleja las problemáticas macro, se plantea en el grupo que la relevancia del trabajo del maestro pasaría, también, por su capacidad de "diagnosticar problemas sociofamiliares y enfermedades".

En este marco el grupo alude a la responsabilidad y al deseo de "atender a las necesidades" de los niños que son diferentes (y que necesitarían más o menos ayuda pedagógica, de acuerdo a su nivel de desarrollo y madurez), identificando a la diferencia con la deficiencia: el trabajo con niños con problemas físicos o psicosociales son referenciados como una parte importante de los problemas que han de enfrentar como maestros. Probablemente, en este "tipo de niños" el grupo estaría depositando la ansiedad que provoca el trabajar con la diferencia, quedando planteada la alternativa de excluirlos como solución al problema de "no saber cómo atenderlos".

También en este grupo la paradójica relación existente entre la alta relevancia asignada al trabajo docente y su escaso reconocimiento económico quedan contrapuestos a la "recompensa del carińo y aprendizaje de los niños", como elemento reparador y gratificante distintivo de la profesión. Desde la perspectiva grupal, "la escasa remuneración económica" y el desprestigio generalizado de la profesión -“compensada con las gratificaciones" que suponen el aprendizaje de los nińos y el afecto que ellos brindan- se concibe como el principal obstáculo para la calidad del trabajo docente.

Así, el grupo parece defenderse del conflicto y el sufrimiento desde un relato que siempre contrapone, a la descripción de la realidad, las satisfacciones internas que no están a primera vista y que tienen que ver con los vínculos afectivos (con los niños y la profesión). La principal satisfacción que este trabajo acarrea se ejemplifica con anécdotas y vivencias que dan cuenta de cómo el maestro ingresa al niño al mundo simbólico, enseñándole a leer, escribir, hablar (aprendizajes que aluden a lo más básico de la escolarización).

El grupo también aludió a las tensiones que genera la diversidad de tareas que institucionalmente hay que "cubrir" y la "multiplicidad de lugares que hay que asumir" (madre, amiga, compañera, réferi, confidente). El trabajo del maestro vinculado a la formación en valores queda, según los entrevistados, relegado a un segundo plano, desdibujado y dificultado en un contexto institucional que plantea variadas 
exigencias de eficacia. A la exigencia de "cubrir todos los temas de un programa” en un período de tiempo determinado -generalmente, vivido como escasopara lograr en los alumnos aprendizajes que han de ser calificados en las instancias evaluativas correspondientes se suman otras tareas de diversa índole (burocráticas, institucionales, extracurriculares).

La singularidad de los contextos áulico, institucional y social a los cuales tiene que responder la labor docente es un significante que emergió recurrentemente, girando en torno a la idea de que no es posible pensar que hay una sola manera de asumir la tarea pedagógica: el maestro y su propuesta "tienen que adaptarse" al contexto para poder ser pertinente a sus necesidades.

El buen hacer docente queda asociado tanto a su capacidad de acomodarse a las circunstancias concretas en las que se desarrolla como a su eficacia, en términos de aprendizaje constatable en los niños. En este sentido, la posibilidad de llevar adelante prácticas innovadoras se acota, pues los nuevos docentes se ven compelidos a encaminar sus propuestas en función de las dinámicas áulicas y formas de abordaje de los contenidos ya instituidas, en vista a alcanzar una mínima eficacia en el hacer.

Este grupo plantea que la profesión elegida los involucra en su totalidad: en la cual "hay que dar mucho (lo mejor) de sî" y en la que "hay que tener amor" (a los niños, pero también a la carrera) y estar dispuesto a atravesar una constante "superación personal". Superación que se inscribe tanto en la concepción de la formación continua (capacitación permanente), como en la idea de un trabajo continuo con uno mismo. De allí, "ser maestro implica algo más que tener la titulación": ser maestro es ser un "buen maestro", con una actitud y un compromiso que no otorga una preparación profesional.
Si bien el discurso comienza a ser pensado desde la propia experiencia de práctica, en algunos momentos se fue convirtiendo en un discurso prescriptivo acerca de lo que "debe ser", estructurado en torno a una crítica abierta a algunos maestros que se han conocido en las prácticas: "maestros sin vocación" (que parecen odiar a sus alumnos), que eluden su responsabilidad social y que "golpean psicológicamente" a los niños. La oposición entre "lo bueno" y "lo malo" del ejercicio de la profesión cruzó la producción grupal, vinculada a las experiencias con maestros que planifican sus clases, que tienen compromiso, que tienen un rol formativo en las prácticas versus los que no tienen autoridad, los que son irresponsables, los que tienen una visión negativa de los niños e instauran con ellos una relación de temor.

Desde diversas ejemplificaciones, la "relación amor-odio" a los niños se convierte en un significante central en diferentes momentos de la reflexión grupal: amor que sostiene, aversión que se despierta con las tensiones, cuando no se trabaja sobre ellas o cuando no se tiene vocación.

Ahora bien, en diferentes momentos de la producción discursiva del grupo, el lugar de los maestros que critican se presenta como inminente futuro que se prefiere ignorar (o no abordar), como negación de la angustia que provoca tanto el conocer las condiciones laborales que en un futuro se asumirán como las dificultades para alcanzar el ideal (estigmatizado en el maestro bueno) durante el desempeño profesional.

El grupo se vale de la metáfora del "doble filo" para referirse a la ambivalencia de trabajar con otros, con niños (ver Esquema 2): el trabajo que se puede ejercer sobre ellos puede tener simultáneamente y en un mismo movimiento tanto consecuencias buscadas, positivas y deseables (se los puede cuidar, mover, sacar adelante) como efectos no buscados, negativos y no deseados (se los puede dañar, estancar, etiquetar). 


\section{Esquema 2}

Ambivalencias en el desempeño de la tarea

\section{TRABAJO DOCENTE: TRABAJO AMBIVALENTE}

\section{PROPÓSITOS}

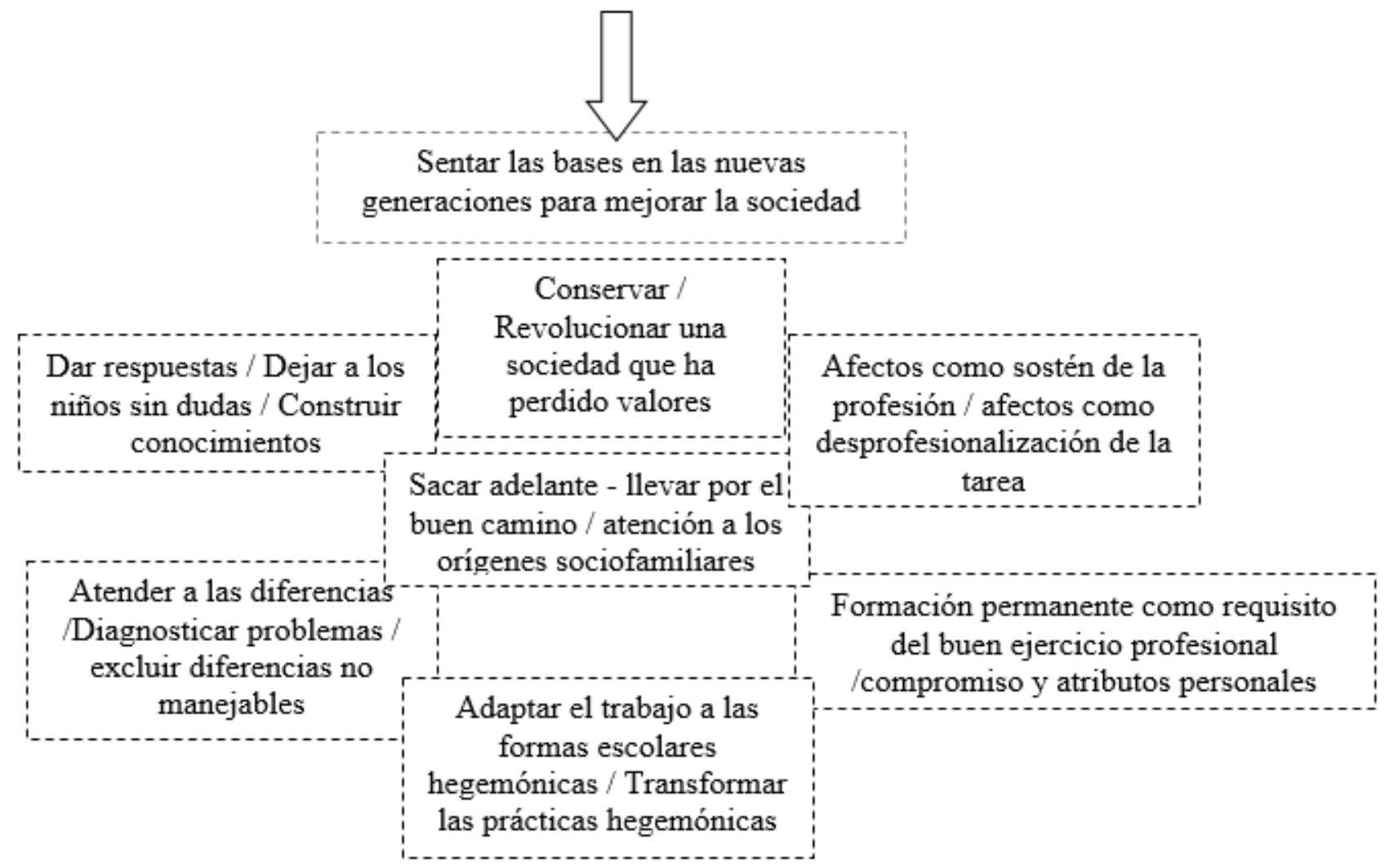

\section{Todo tiempo futuro será mejor}

El grupo del octavo semestre, compuesto por ocho estudiantes, inicia la reflexión en torno a aquello que el ejercicio de la práctica permite: "darse cuenta" ... darse cuenta de las motivaciones que los sostienen en la carrera y de que la situación subjetiva en la que se encontraban en un inicio ya no es la misma hacia el final de su cursado. Al respecto, se hace explícita referencia a dos facetas del trabajo docente, las cuales, vinculadas, estructurarán gran parte de la producción grupal: una faceta más inmediata, la interacción con los niños, y otra, más trascendental, la misión socioeducativa del maestro. Así, el trabajo con los niños es pensado como un trabajo de índole social, cuyo sentido excede ampliamente el suceder de la interacción cotidiana en las aulas.

El trabajo docente queda también referido a la posibilidad de "ampliar horizontes" y de "abrir los ojos para poder mirar realidades" desconocidas e, inclusive, la propia realidad, con el sentido de sacarlos (a los alumnos) de un conformismo - "moverlos de lugar"en el que, aparentemente, estarían inmersos como parte de la sociedad. Abrir panorama, "abrir puertas" 
y "darles armas para enfrentar esa realidad" son significantes ligados a la responsabilidad que tiene el maestro, con los niños y con México. Así, la responsabilidad y el compromiso de la profesión no solo están dados con relación a las prescripciones que hay que cumplir, sino, y más importante, con la perspectiva de ofrecer a los niños una formación para la vida.

La formación integral para la vida, significada como objetivo central del trabajo docente, queda recurrentemente aludida en un doble sentido: "una formación pragmática” (brindarles conocimientos y habilidades que puedan usarse) y "una formación en valores para integrarse a la sociedad". La posibilidad de llevar adelante esta tarea se vería dificultada por la cantidad de tareas cotidianas y obligaciones - en general ligadas a lo administrativo- a las que se enfrenta el maestro, en un tiempo limitado. El tiempo emerge como un significante que cruzará toda la producción grupal: el tiempo de las obligaciones, contrarrestando el tiempo para lo verdaderamente importante.

Así, el contexto de trabajo es entendido como un elemento de importancia que incide sobre la tarea del maestro, tanto en el vínculo con los niños como con los padres: las presiones por lo que hay que cumplir y hacer, la relación que se establece con los otros (quienes elaboran diferentes demandas desde lugares disímiles), el no manejo del tiempo encaminan los esfuerzos del trabajo hacia otra dirección, diferente a la deseada. Esto se constituye en fuente de insatisfacción que se acrecienta por la escasa posibilidad de ver los resultados, que son de largo plazo y que se vinculan con lo implícito de las formas de enseñanza, más que con el aprendizaje del contenido concreto.

Contrapuesta a la descripción de las dificultades que se presentan en el ejercicio de la tarea docente, emerge el significante de "la realización personal" basada en satisfacciones ligadas al vínculo con los niños. Un vínculo afectivo y profesional, en el cual se puede mirar la pertinencia del propio hacer: a través del aprendizaje de los niños y del gusto que ellos demuestran ante la modalidad de trabajo propuesta.

Cuando el grupo comienza a pensar en el futuro, la producción se organiza dilemáticamente en un vaivén que lo hace oscilar entre "el deseo de cambio" y las condiciones institucionales que lo dificultan. Cabe señalar que, en este momento de la producción grupal, se plantea un dilema que el grupo dramatizará a partir de una escisión en la que algunos se posicionan desde el lugar de practicantes idealistas que anhelan llevar a cabo un cambio y otros desde el lugar de futuros maestros ya recibidos cuyos anhelos se ven frustrados por las condiciones institucionales de trabajo.

El significante del "cambio", que se enuncia desde un inicio, es retomado en diferentes momentos de la producción grupal, cada vez con mayor fuerza discursiva. El grupo se refiere así al "cambio de las formas y los tipos de contenidos de la enseñanza", al "cambio del tipo de relación docente-alumnos", al "cambio de la escuela", al "cambio del mundo".

Paralelamente, el grupo también elabora la noción de adaptación como propia del trabajo del maestro (y del practicante): "adaptarse y adaptar las propuestas de enseñanza al contexto, a la institución, al grupo, a los maestros, a lo prescripto". Esta paradoja, que está en la base de la producción, se juega también en el sentido que el grupo atribuye a la tarea docente: cambiar el mundo a través de la educación - adaptarse como condición que posibilita el acto educativo.

En este marco, se torna recurrente el emergente del maestro como aquel que se adapta y adapta su propuesta al contexto y a los intereses de los niños, ligado a la frustración que provoca un panorama futuro que parece no dejar lugar para el cambio (condensado en la formación integral y humana). Este emergente del futuro próximo llega al grupo también desde la voz de los maestros, como portavoces de la profecía que (les) anuncia que, una vez recibidos, los nuevos maestros terminarán siendo como ellos (los viejos).

Situados en el lugar de practicantes, se plantea la necesidad de "adaptarse a la modalidad de trabajo que los nińos vienen teniendo con el maestro titular", como única posibilidad de establecer un vínculo con ellos y de estos con el conocimiento. Se trata de un vínculo que no puede establecerse desde la innovación absoluta, ya que para que los niños respondan al trabajo propuesto es necesario partir de los modos de relación -entre ellos, con el conocimiento y con 
el maestro- conocidos por ellos; de otro modo, entienden, se les generaría confusión (quizás la que están experimentando ellos en el lugar de alumnos de profesorado).

En el planteo grupal, el futuro se presenta como promisorio a partir del egreso de la Normal, imaginando un escenario en el que ya no estarán compelidos a amoldarse a formas y concepciones ajenas, en tanto contarán con la posibilidad de: tener un grupo propio, por un tiempo prolongado, sin una segunda mirada perturbadora, lo cual, además de habilitar una relación de respeto y autoridad, posibilitará un trabajo autónomo desde una construcción propia, basada en concepciones también propias.

El emergente libertad-cohibición estructura gran parte de la producción, signada por la esperanza de obtener la libertad con la titulación, al romper el vínculo con los profesores de la institución formadora y las escuelas primarias que evalúan, observan, controlan, autorizan el propio hacer, solicitando constantes adaptaciones de acuerdo al estilo propio. Los practicantes entienden que todo lo aprendido en las prácticas será el motor de las prácticas que diseñen y lleven a cabo con posterioridad a la graduación.

Ahora bien, pensarse en un futuro cercano enfrenta a los practicantes con un conflicto interno que los lleva a imaginarse como protagonistas de dos escenarios contrapuestos: sea constreñidos en su hacer por las condiciones institucionales reales que han conocido durante las prácticas pre-profesionales; sea con la libertad y capacidad para superar tales condiciones e implementar las propuestas ideales de cambio que vienen sosteniendo como parte de una nueva generación. Se trata de dos posibilidades contrapuestas que se postulan como imperativos objeto de debate: "cansarse", "darse por vencido" (opción probable y repudiada que implica asumir el lugar del maestro duramente criticado, pero que evitaría la desilusión de intentar hacer algo que no se puede) / tomarlo como "un reto", "hacerse más fuerte" (opción improbable y valorada). El abandono de la carrera se plantea como la opción más pertinente si antes se abandona el idealismo, en un momento de la reflexión grupal signado por la discusión y fuerte polarización de posturas.
La producción grupal oscila, pendularmente, entre "lo que ocurre" (encarnado en lo que hacen los maestros de las escuelas primarias que los han acompañado en sus prácticas) y "lo que debiera ocurrir" (lo que intentan hacer los practicantes, lo que procurarán hacer como maestros). La pregunta por la que el grupo pareciera batallar es ¿qué hacer con el idealismo y con el conocimiento de las condiciones propias de la realidad escolar cotidiana? El grupo elabora entonces la noción de cambios parciales, en tanto el cambio radical es imposible, lo cual lleva a plantear que, paulatinamente, de generación en generación, se podrán lograr los cambios que, hasta ahora, parecían dar sentido al ejercicio de la profesión.

Por otra parte, el buen trabajo del maestro se asocia con el compromiso y con la necesidad de superación personal y profesional, que también habrá de promoverse en los niños: en esta relación, subyacen las ideas, luego explicitadas, de que no se podría dar a los alumnos lo que no se tiene y de la importancia que tiene poder "dar el ejemplo" (ser capaz de hacer lo que se les pide a los alumnos que hagan) como eje del vínculo maestro-alumno.

Este emergente (de la superación personal, generalmente asociado al "estar actualizado", "en formación permanente" y complementada con la noción de experiencia como única forma de adquisición de los saberes docentes) aparece con insistencia en diferentes momentos de la producción grupal y se vincula con la noción de "un mundo en constantes cambios" que obligarían a la labor educativa y a los sujetos que la emprenden a someterse continuamente a un proceso de transformaciones.

El cambio, a la vez que inscribirse en un deseo interno por trasmutar formas instituidas, se asocia a un proyecto que trasciende a los futuros nuevos docentes y que ellos tienen que viabilizar: el proyecto del constructivismo instrumentalizado por el nuevo plan de estudios, del cual todavía no se han visto resultados. El pensarse como "ratoncitos de laboratorio" da cuenta, además del lugar que se ocupa en el proyecto de cambio, de la sensación de inseguridad que provoca estar en una situación cuyos resultados aún son inciertos. 
Ante un panorama tan desalentador, el deseo de ejercer el trabajo docente emana de una fuente: el amor por lo que se hace. El "amor a la profesión", estar "enamorado" permite organizarse, y, podría agregarse, permanecer "ciego" ante las limitaciones. La fuerte limitación que constituye el bajo salario de los docentes se percibe no ya como dificultad, sino como una ventaja: "te pagan por hacer lo que te gusta".

Así, "amor" y "formación" son planteados como dos requisitos para el (buen) ejercicio del trabajo docente. Lo que el grupo rescata de la formación es su "potencial para sensibilizar" acerca de lo que significa trabajar con niños (más allá de los conocimientos teórico-prácticos que se necesitan para ello) y con toda la realidad escolar.
Reconocerse como resultado de esa enseñanza tradicional que critican es otro movimiento que hace el grupo en su intento por salir de la dicotomización que invade la producción: "las formas tradicionales pueden tener algo rescatable", "los cambios que procuramos llevar a cabo no son siempre $100 \%$ positivos". Combinar elementos, en función de su utilidad y su funcionalidad a cada grupo particular, es una salida que el grupo elabora, posicionándose desde una noción de constructivismo desde donde propiciar esta combinación, basada en un criterio de eficiencia. Tratar de evitar las falencias de la propia formación es un emergente que, sobre el final, sirve para otorgar sentido a la noción de cambio (ver Esquema 3).

\section{Esquema 3}

Responsabilidad social a futuro

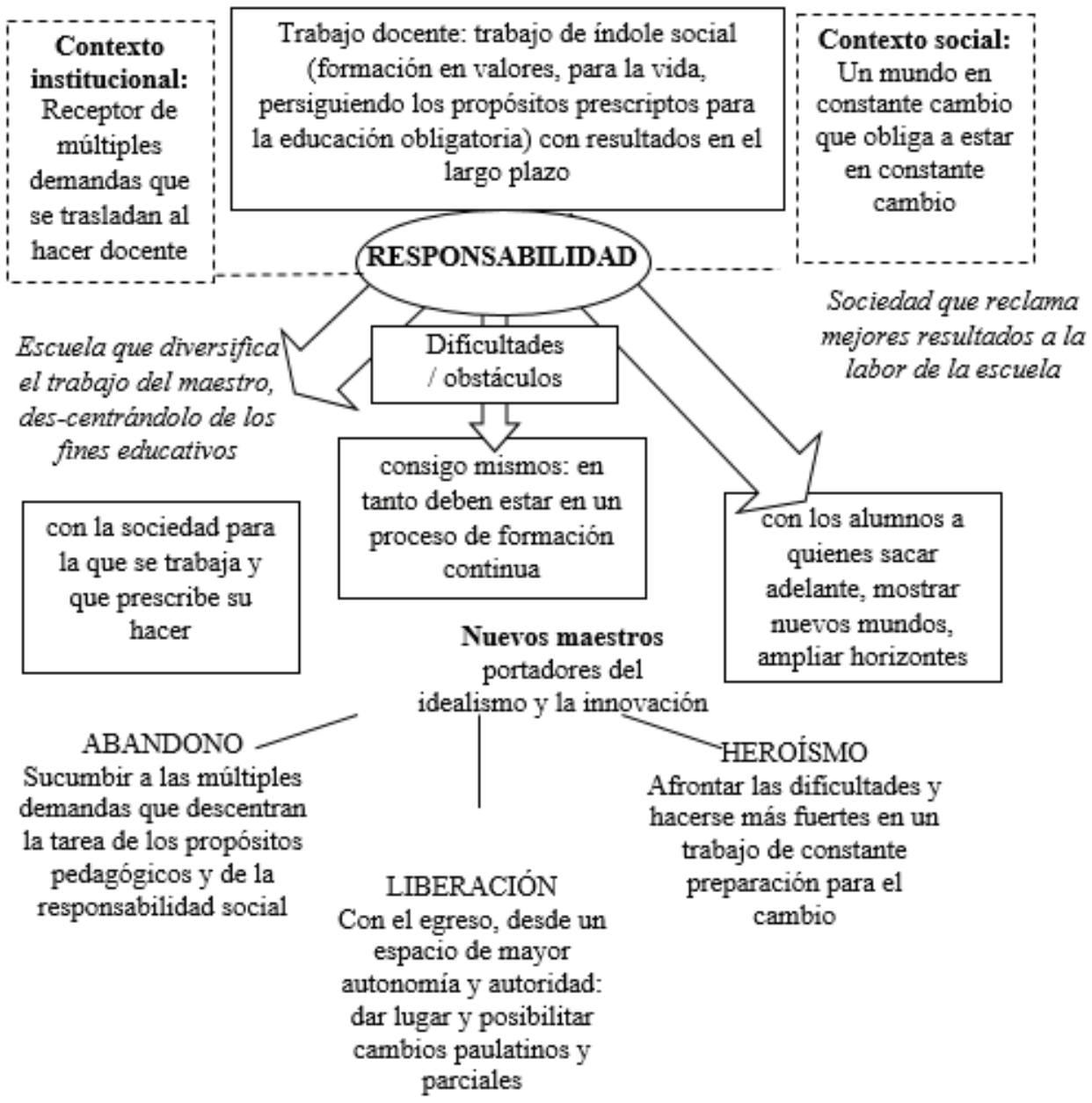




\section{Conclusiones y discusiones}

Siguiendo los análisis hasta aquí expuestos, estamos en condiciones de afirmar que las primeras experiencias de intervención pedagógica suponen para el sujeto futuro docente una movilización de creencias, emociones y significados que venía portando como estudiante y que, al tiempo que pugnan por prevalecer en la interpretación de la realidad vivida, se ponen en signo de interrogación interpelando al propio hacer. Se trata de una movilización advertida ya en la bibliografía especializada (Edelstein y Coria; 1995; Edelstein, 2011; Alliaud, 2019; Sanjurjo, 2017) que está lejos de quedar restringida al plano didáctico, intelectual y cognitivo; de allí la importancia de proponer un enfoque socio-psíquico e histórico-cultural que tome como protagonista al sujeto y sus prácticas (atravesadas afectiva y subjetivamente) e inscriptas en el contexto de las "dinámicas y transformaciones materiales y simbólicas de una determinada sociedad" (Kaplan, 2018, p. 10).

Quienes se inician en la docencia no solo deberán atenerse a las exigencias institucionales pautadas para el ingreso a la profesión, sino que, además -y este es el aporte que hace el análisis aquí presentado- deberán reposicionarse subjetivamente frente a los componentes de la cultura profesional y hacer una apropiación singular de estos para estar en condiciones de asumir el rol. En ese sentido, resulta pertinente el señalamiento de Alliaud (2019) cuando plantea que los docentes en formación (en los trayectos de práctica) necesitarán incorporar, junto a las capacidades "técnicas" del oficio, el compromiso con la tarea (con la que se identifican claramente los sujetos de la muestra) y la confianza en las posibilidades de los sujetos que aprenden, en la propia tarea y en la institución escolar "como instancia legítima para la transmisión sistemática, pautada, masiva y compartida de un acervo cultural "común" a las nuevas generaciones" (p. 15).

Al respecto, el material analizado señala que las primeras experiencias de prácticas, por un lado, permiten a los futuros docentes la construcción de un compromiso (con la sociedad, la transmisión cultural, la formación de las generaciones futuras) pero, por el otro lado, le dificultan la confianza sobre el poder y alcance de su accionar pedagógico.

En tanto se trata de instancias que obligan (al sujeto en formación) a repensar la docencia y las formas posibles de asumirla (con y más allá de las conceptualizaciones revisadas en la formación superior), se sostiene en este trabajo la importancia de atender a la complejidad que esta interpelación supone, incorporando como dimensión ineludible de la formación a la subjetividad del sujeto futuro docente (siempre situado en un contexto): dimensión que se propone como eje de acción-reflexión desde la Pedagogía de la formación (Filloux, 1996; Ferry, 1997; Anzaldúa Arce, 2009; Souto, 2016) y cuya relevancia es reconocida desde las producciones dedicadas a estudiar el campo de la práctica en la formación docente (Edelstein y Coria, 1995; Anijovich, Cappelletti, Mora y Sabelli, 2009; Marcelo y Valliant, 2019; Sanjurjo, 2017).

Retomando las preguntas que orientaron el análisis del material expuesto, se observa en las producciones discursivas que las (primeras) experiencias de intervención pedagógica de los practicantes derivan en una caracterización del trabajo docente como un trabajo que -excediendo ampliamente lo acontecido en la interacción cotidiana del aula y la institución escolarpretende, en lo fundamental, ayudar a los nińos a integrarse a la sociedad, con énfasis en la idea de "asistencia", que podría acercarse a la idea de "asistencia social". Por esto, ejercer el trabajo docente implica una responsabilidad, tanto con los niños (pues contribuye a integrarlos en la sociedad: "sacándolos adelante", dándoles valores y conocimientos para la vida) como, fundamentalmente, con la sociedad (contribuye a la formación de los ciudadanos del futuro).

Entonces, no es solo la "plaza segura", la "supuesta sencillez" del trabajo o "el amor por los niños" los que permiten sostener una opción profesional socialmente depreciada. Provistos de las significaciones que la institución formadora les ha ofrecido, los sujetos futuros docentes otorgan sentido a tal elección y a su labor cotidiana en las escuelas a partir de una identificación 
con los discursos de la vocación y el compromiso social, desde significaciones que se acoplan a deseos singulares vinculados al cambio social y a la democratización del vínculo pedagógico. No es la enseñanza (de conocimientos y saberes a transmitir) lo que vuelve convocante al mundo de la profesión, sino las funciones de socialización (merced a la disciplina escolar) y subjetivación (tendiente a que los sujetos sobre los que se trabaja desarrollen su potencial) que tienen lugar (Dubet, 2002), mediadas afectivamente, y que dotan de relevancia social a la tarea.

Es lo que no se ve (lo interno y lo que excede al aula) y lo que no se puede medir en el corto plazo (lo que los exámenes no pueden "asir" en una calificación) lo que permite otorgar sentido al trabajo docente: tanto en un plano social, como en un plano personal. Poniendo en primer plano la lógica de la relación por sobre las lógicas del servicio y del control social (Dubet, 2002), los futuros docentes entienden que la singularidad de la profesión está dada por ser un trabajo cuya materia prima son sujetos, que se sostiene en una dialéctica de dar-recibir: dar a los alumnos conocimientos y valores, pero también cariño, amor, comprensión; recibir de los alumnos cariño, amor, reconocimiento, como pago simbólico que da sentido al trabajo docente y que compensa ampliamente el escaso reconocimiento material. El vínculo afectivo y profesional con los niños se constituye en fuente de sentido y satisfacción personal: la profesión pasa a ser así un modo de realización personal.

Planteada como relación dialógica, de intercambio recíproco de afectos, saberes y experiencias, pareciera minimizarse o borrarse, en un plano imaginario, la asimetría que hace al lugar del docente y al de los alumnos. Podría pensarse que, junto a otros factores, esta negación de las diferencias (la cual, probablemente, es producto de la situación de pasaje que los futuros nuevos docentes están transitando) contribuye también a la recurrentemente aludida dificultad por lograr ser vistos, por los alumnos, como sus "maestros".

Para los practicantes, el "buen docente" queda definido por sus atributos y cualidades personales (atendiendo a "lo que tiene para dar" y su disposición a "recibir"), más que por su "capacidad técnica" para portar el legado cultural que la escuela le pide transmitir. No obstante reconocer la importancia de una sólida formación profesional para llevarlo a cabo, prevalece la idea de que se trata de un trabajo cuyo desempeño requiere mucho más que un saber transmitir conocimientos. Es un trabajo que involucra a los sujetos en su totalidad, siendo ellos (los sujetos) instrumento central. Como señalaba uno de los grupos: "se trabaja con humanos, no con máquinas", aludiendo a cómo la intersubjetividad está cruzada por los afectos, pero también por lo imprevisible, por lo no programable y por lo falible. En este sentido, no hay formación que alcance si el sujeto no cumple con dos prerrequisitos indispensables: la vocación-convicción en la elección profesional (lo cual signa a la docencia de un rasgo singular que la diferencia del resto de las profesiones) y el compromiso social con su tarea.

Por otra parte, los discursos grupales evidencian una autopercepción de los futuros docentes, como una nueva generación, que propone una ruptura con las formas instituidas de enseñanza, que los diferencian de los maestros formados en enfoques anteriores. Se trata de una generación que propicia un cambio, basado en los fundamentos teóricos de la formación que, de algún modo, "anclan" en el deseo de propugnar experiencias educativas diferentes a las vivenciadas por ellos como alumnos.

Esta autopercepción es validada por los demás (niños y maestros) que esperan, en la tarea del practicante, la presentación de una propuesta diferente a la de los maestros ya recibidos. Esto provoca que los practicantes vivan la innovación como una demanda, un imperativo o una presión por hacerse cargo de un cambio que les resulta, por falta de modelos, difícil de implementar. Expresiones como "ahora ya viene el nuevo enfoque", "ahora se pretende que los alumnos construyan su conocimiento", "tenemos que tomar... partido y unirnos al constructivismo" dan cuenta de la relativa ajenidad con que los practicantes se vinculan con un cambio propuesto por otros.

Ahora bien, en la descripción de lo que sucede en las prácticas de novatos y expertos, el contexto socio-institucional se identifica como una dificultad central 
en la implementación del cambio mencionado. Por un lado, la escuela es percibida como una institución que, en parte, está regida por una lógica de mercado, sustentada en los patrones de la economía, la rapidez y la seguridad en la consecución de sus objetivos, en búsqueda de unos resultados que puedan medirse, evaluarse (Pérez Gómez, 1998) y mostrarse para dar cuenta de la pertinencia de su funcionamiento.

De acuerdo a las vivencias de los practicantes, en su labor cotidiana los docentes están compelidos a atender múltiples y variadas demandas (que exceden lo pedagógico), en condiciones materiales que distan de ser las ideales. Pero además esas demandas no provienen solo de las instituciones o de los aparatos burocráticos del Estado, sino que provienen, también, de los mismos niños contemporáneos. Ellos -caracterizados como activos, curiosos, hábiles, inteligentes, astutosson identificados, junto con sus familias, como exponentes de un mundo social en proceso de profunda y continua transformación que rompe con los consensos respecto al valor de la escuela, los valores que esta ha de transmitir y los modos legítimos de hacerlo.

Los niños, la sociedad, el contexto laboral e, incluso, la propia formación, se erigen como obstáculos a sortear en la consecución de la tarea: hay que realizar un trabajo "en contra" de ellos, en búsqueda de su transformación. Intento de transformación que se convierte en fuente de sufrimientos, ante los cuales la profesión comienza a ser ejercida en un repliegue en las viejas formas conocidas-criticadas-efectivas. Situación que conduciría a un "sufrimiento ético" (Dejours, 1998; Vázquez Peña, 2019), por traicionar los propios ideales y valores (respecto al "trabajo bien hecho") en el ejercicio de la tarea profesional.

Siguiendo los planteos de la psicodinámica del trabajo, estamos haciendo referencia al sufrimiento que provoca el no poder satisfacer las exigencias que socialmente se le demandan, atendiendo a la carencia de un saber-hacer que haga eficaz la realización del trabajo; al sufrimiento que provocan los sentimientos ambivalentes implicados en el trabajo con los niños, asociados a los temores de hacer daño (con el trabajo mal hecho) y a perder el control de la situación pedagógica; al sufrimiento que provoca el escaso recono- cimiento (Dejours, 2013); al sufrimiento que genera la percepción del malestar docente, de la insatisfacción personal en que muchos de los maestros recibidos desempeñan sus labores.

De lo expuesto se deriva que la etapa de la socialización profesional objeto de estudio se experimenta como un proceso de adaptación a un mundo laboral y escolar que es criticado por su anacronía respecto de la sociedad e infancias contemporáneas y de las corrientes pedagógicas revisadas en el plano teórico durante la formación inicial. El deseo de constituirse en una generación del cambio pedagógico sucumbe, durante esta fase de la socialización, no solo ante unas condiciones laborales que se condicen con la depreciación social de la profesión, sino también ante los rasgos de una cultura profesional que se erige en torno a los significados del control y la eficacia del propio hacer, y que orienta la (auto)justificación de dicho hacer (y sus resultados) apoyándose en un discurso del malestar docente.

Ahora bien, no se trata de un camino sin salida o de una única forma posible de transitar la iniciación a la profesión: las problematizaciones, los análisis y dispositivos propuestos en los últimos años desde el campo de la formación docente (Edelstein, 2011; Alliaud, 2017; Sanjurjo, 2017; Anijovich, 2019; Marcelo y Valliant, 2019) no hacen más que resaltar la importancia de atender a la complejidad que revisten los fenómenos educativos y a su anudamiento en la perspectiva de un sujeto (psíquico y social) produciendo tensiones y contradicciones a las que es preciso atender para que la (trans)formación tenga lugar, especialmente en un mundo cambiante como el que vivimos.

De allí la relevancia de aportar conocimientos que den cuenta del modo en que las primeras experiencias pedagógicas en el campo socioprofesional son subjetivamente significadas por los futuros docentes, atendiendo a la dimensión socioemocional del proceso formativo: a los saberes, no saberes, supuestos, valores y afectos que se ponen en juego... Pero no para volverlos objeto de una educación emocional que intente "direccionarlos", "gestionarlos" o "regularlos" (Furlán y Ochoa Reyes, 2018) , sino para tomarlos como objeto central de una reflexión que habilite la simbolización 
y resignificación de las maneras de pensar y sentir, la comprensión de las razones por las que actuamos de un modo u otro, la elucidación del impacto subjetivo que supone el trabajo pedagógico con niños en los contextos escolares del tercer milenio; todo aquello en el camino de proponer recuperar autonomía y poder sobre la propia práctica docente.

\section{Referencias}

Achilli, E. (2000). Investigación y formación docente. Laborde Editor.

Alliaud, A. (2017). Los artesanos de la enseñanza: acerca de la formación de maestros con oficio. Editorial Paidós.

Alliaud, A. (2019). El campo de la práctica en la formación docente. Material de trabajo para educadores y educadoras. Cuadernos del IICE, (1), 7-38.

Anijovich, R. (2019). Orientaciones para la Formación Docente y el Trabajo en el aula: Retroalimentación Formativa. Editorial SUMMA.

Anijovich, R., Cappelletti, G., Mora, S. y Sabelli, M. (2009). Transitar la formación pedagógica: dispositivos y estrategias. Editorial Paidós.

Anzaldúa Arce, R. (2009). La formación: una mirada desde el sujeto. En $X$ Congreso Nacional de Investigación Educativa. Procesos de formación, (15), 1-10.

Araujo, G. y Fernández, L. (1996). La entrevista grupal: herramienta de la metodología de investigación. En I. Szasz y S. Lerner (comps.), Para comprender la subjetividad. Investigación cualitativa en salud reproductiva y sexualidad. Editorial El Colegio de México.

Bedacarratx, V. (2012). Futuros maestros y la construcción de una identidad profesional: una mirada psicosocial a los procesos que se ponen en juego en los trayectos de formación en la práctica. Revista Electrónica de Investigación Educativa, 14(2), 133-149. http://redie.uabc.mx/vol14no2/ contenido-bedacarratx2012.html

Baz, M. (1996). Intervención grupal e investigación. Cuadernos del Tipi 4. Universidad Autónoma Metropolitana-Xochimilco, México.
Baz, M. (1998). La tarea analítica en la construcción metodológica. En D. González Ángeles, E. Vargas; I. Jáidar, Encrucijadas metodológicas en Ciencias Sociales. Universidad Autónoma Metropolitana-Xochimilco.

Dejours, C. (1988). Nota de trabajo sobre la noción de sufrimiento [trad. María José Acevedo]. En Plaisir et souffrance dans le travail. Editorial de L'AOCIP.

Dejours, C. (2013). Trabajo vivo. Trabajo y Emancipación (vol 2). Editorial Topía.

Dubet, F. (2002). El declive de la institución. Profesiones, sujetos e individuos en la modernidad. Editorial Gedisa.

Dubet, F. (2007). El declive y las mutaciones de la institución. Revista de antropología social, 16, 39-66.

Edelstein, G. (2011). Formar y formarse en la enseñanza. Editorial Paidós.

Edelstein, G. y Coria, A. (1995). Imágenes e imaginación. Iniciación a la docencia. Editorial Kapeluz.

Ferry, G. (1997). Pedagogía de la formación. Editorial Novedades Educativas.

Filloux, J. C. (1996). Intersubjetividad y formación. Ediciones Novedades Educativas.

Furlán, A. y Ochoa Reyes N. (2018). Educar las emociones como un problema ético. En C. Kaplan (Ed.), Emociones, sentimientos y afectos. Las marcas subjetivas de la educación. Editorial Miño y Dávila.

Hernández Mella, R., Pacheco-Salazar, B., Liranzo Soto, P. y Jiménez Soto, A. (2018). "Yo quería ser...": la voz de maestras de educación primaria. Ciencia y Educación, 2(1), 51-59. http://dx.doi. org/10.22206/cyed.2018.v2i1.pp51-59

Kaplan, C. (2018). ¿Hacia una revolución simbólica de la afectividad en el ámbito educativo? En C. Kaplan (Ed.), Emociones, sentimientos y afectos. Las marcas subjetivas de la educación. Editorial Miño y Dávila.

Marcelo, C. y Vaillant, D. (2019). Hacia una formación disruptiva de docentes: 10 claves para el cambio. Narcea Ediciones. 
Neiman, G. y Quaranta. G. (2006). Los estudios de caso en la investigación sociológica. En I. Vasilachis de Gialdino (Coord.), Estrategias de investigación cualitativa. Editorial Gedisa.

Pérez Gómez, A. (1998). La cultura escolar en la sociedad neoliberal. Editorial Morata.

Ramírez Grajeda, B. y Anzaldúa Arce, R. (2017). Subjetividad y socialización en la era digital. Argumentos, 27(76), 171-189.

Remedi, E. (2 de abril de 2004). La intervención educativa [Conferencia Magistral]. Reunión Nacional de Coordinadores de la Licenciatura en Intervención Educativa de la Universidad Pedagógica Nacional, México, DF. https:/elvs-tuc.infd. edu.ar/sitio/nuestra-escuela-formacion-situada/ upload/Conferencia_Eduardo_Remedi_1_.pdf
Sanjurjo, L. (2017). La formación en las prácticas profesionales en debate. Revista del Cisen Tramas/ Maepova, 5(2), 119-130.

Schön, D. (1998). El profesional reflexivo. Cómo piensan los profesionales cuando actúan. Editorial Paidós.

Souto, M. (2016). Pliegues de la formación. Sentidos y herramientas para la formación docente. Homo Sapiens Ediciones.

Tardif, M. y Moscoso, J. N. (2018). La noción de "profesional reflexivo" en educación: actualidad, usos y límites. Cuadernos de Pesquisa, 48(168), 388-411.

Vázquez Peńas, A. (2019). Trabajo, sufrimiento e ideología en la sociedad neoliberal. Oximora. Revista Internacional de Ética y Política, 0(15), 15-32. https://doi.org/10.1344/oxi.2019.i15.28120 